\title{
DIREITO AMBIENTAL E NANOTECNOLOGIAS: DESAFIOS AOS NOVOS RISCOS DA INOVAÇÃO
}

\author{
Juliane Altmann Berwig ${ }^{1}$ \\ Universidade Feevale
}

Wilson Engelmann ${ }^{2}$

Universidade do Vale do Rio dos Sinos (UNISINOS)

André Rafael Weyermuller ${ }^{3}$

Universidade FEEVALE / Universidade do Vale do Rio dos Sinos (UNISINOS)

\section{RESUMO}

Propõe-se avaliar a complexidade que as novas tecnologias representam, sobretudo na utilização das nanotecnologias em inúmeros produtos que, a priori, foram desenvolvidos para proporcionar melhorias e não para causar danos futuros. Por meio de uma pesquisa descritiva e bibliográfica, objetiva-se conhecer os instrumentos tradicionais do Direito Ambiental e avaliar as possibilidades de novos caminhos com a finalidade de conciliar a necessária evolução tecnológica com a prudência em relação às possíveis resultantes imprevisíveis da utilização de elementos desenvolvidos na escala nano. A tutela pelo sistema do Direito Ambiental se desenvolveu sobre uma base antropocêntrica e apresenta uma série de mecanismos classificados dentro das três esferas de

1 Doutora em Direito pela UNISINOS. Mestre em Direito pela UNISINOS. Especialista em Direito Ambiental Nacional e Internacional pela Universidade Federal do Estado do Rio Grande do Sul (UFRGS). Graduada em Direito pela Universidade de Santa Cruz do Sul (UNISC). Professora no curso de Direito da FEEVALE e Pesquisadora com o projeto Os impactos humano-ambientais gerados pelas nanotecnologias: redesenhando os elementos estruturantes do direito ambiental. Presidente da Associação Gaúcha dos Advogados de Direito Ambiental Empresarial (AGAAE). Autora do livro Direito dos Desastres na Exploração offshore do petróleo. Sócia-proprietária do escritório Berwig Advocacia. ORCID: http://orcid.org/0000-0002-9050-8531 / e-mail: julianeberwig@feevale.br.

2 Pós-doutorado em Los retos actuales del Derecho Público pelo Centro de Estudios de Seguridad de la Universidad de Santiago de Compostela (CESEG/USC). Doutorado e mestrado em Direito Público pela UNISINOS. Graduação em Direito pela UNISINOS. Coordenador executivo do Mestrado Profissional em Direito da Empresa e dos Negócios da Unisinos. Professor e pesquisador do Programa de Pós-Graduação em Direito da UNISINOS. Professor visitante da Universidad Católica del Uruguay, colaborador de pesquisa do Latin American Nanotechnology \& Society Network, pesquisador associado do Portucalense Institute for Legal Research e do Centro de I\&D sobre Direito e Sociedade. ORCID: http://orcid.org/0000-0002-0012-3559 / e-mail: wengelmann@unisinos.br.

3 Pós-doutor em Direito pela Pontifícia Universidade Católica do Rio de Janeiro (PUC-RIO). Doutor em Direito pela UNISINOS. Mestre em Direito Público pela UNISINOS. Especialista em Direito Ambiental pela FEEVALE. Bacharel em Ciências Jurídicas e Sociais pela UNISINOS. Pesquisador no Programa de Pós-graduação da PFEEVALE. Professor permanente no Mestrado profissional em Indústria Criativa e no Mestrado Acadêmico em Qualidade Ambiental da FEEVALE. Docente permanente no Mestrado Profissional em Direito da Empresa e dos Negócios da UNISINOS. Professor na graduação em Direito da Feevale e da Unisinos. Professor do PRASJUR da UNISINOS. Advogado. Membro do Comitê Jurídico da ACI - Novo Hamburgo. Membro da diretoria da Subseção da OAB de Sapiranga. ORCID: https://orcid.org/0000-0001-5714-6906 / e-mail: andrerw@feevale.br. 
tutela: a administrativa, a penal e a civil. Com o advento de novas demandas, sobretudo a nanotecnologia e suas possíveis utilizações no futuro, alternativas precisam ser construídas para evitar o impedimento do desenvolvimento tecnológico e, ao mesmo tempo, proporcionar-lhe segurança. É possível concluir que a ausência de norma específica para tutelar a utilização de produtos com nanotecnologia não pode ser justificativa para frear o desenvolvimento de novos instrumentos capazes de realizar essa complexa tarefa. Não obstante a necessidade de uma regra específica, a aplicação de princípios de Direito Ambiental, como precaução, prevenção, poluidor-pagador e outras fontes do Direito, representam um caminho viável.

Palavras-chave: Direito Ambiental; nanotecnologias; novos riscos; princípios.

\section{ENVIRONMENTAL LAW AND NANOTECHNOLOGIES: CHALLENGES TO THE NEW RISKS OF INNOVATION}

\section{ABSTRACT}

It is proposed to evaluate the complexity that new technologies represent, especially in the use of nanotechnologies in numerous products that, a priori, have been developed to provide improvements and not to cause future damages. Through a descriptive and bibliographical research, it aims to know the traditional instruments of Environmental Law and to evaluate the possibility of new ways able to reconcile the necessary technological evolution with the prudence in relation to the possible unpredictable result on use of elements developed at the "nano" scale. The protection of the Environmental Law system was developed on anthropocentric basis and presents a series of mechanisms classified within the three spheres of protection, administrative, criminal and civil. With the advent of new demands, especially nanotechnology and its possible repercussions in the future, alternatives need to be built to avoid impeding technological development and, at the same time, providing security. It is possible to conclude that the absence of a specific standard to protect the use of nanotechnology products can't justify the use of new instruments capable of performing this complex task. Despite the need for a specific rule, the application of Environmental Law principles such as precaution, prevention, polluter pays and other sources of law, represents a viable path.

Keywords: Environmental Law; nanotechnologies; new risks; principles. 


\section{INTRODUÇÃO}

A temática ambiental repercute cada vez mais na sociedade, uma vez que diversas demandas surgem dessa complexa relação que se estabeleceu entre o modelo de vida majoritariamente adotado e sua consequente intervenção no meio ambiente para promover sua subsistência. De uma realidade mais previsível e de impactos mais previsíveis que outrora, passou-se para outro patamar de incertezas quanto às consequências futuras das ações tomadas hoje.

O Direito, importante sistema social, tem como principal escopo estabelecer as regras que permitem uma convivência minimamente organizada entre tantas possibilidades e interesses. Essas normas consistem em regras com caráter específico e de maior objetividade, e também em princípios com natureza mais geral e balizadora de todo o sistema. $\mathrm{O}$ Direito Ambiental, enquanto uma especialização do sistema do Direito, tem como objeto justamente essa relação complexa da sociedade e suas necessidades com o meio e suas limitações.

As estruturas tradicionais do Direito Ambiental são aplicáveis a uma ampla gama de possibilidades fáticas, em que se busca prevenir, coibir, recompor, organizar, indenizar e punir as condutas humanas, mediando as ações de nossa existência em relação ao meio ambiente. A responsabilidade civil, a penal e a administrativa são os três grandes ramos ou caminhos que estão assim estruturados para dar conta de todas as possibilidades que essa relação complexa pressupõe.

Com as mudanças de paradigma temporal e das relações entre produção e consumo, somam-se outras possibilidades de danos e de impactos, ainda desconhecidas para o futuro. Tais novidades são produzidas em um contexto comumente denominado de inovação, em que verifica-se uma constante evolução tecnológica que procura atender a novas demandas e necessidades da sociedade. Porém, tais inovações, como as que se desenvolvem na escala nanométrica abrem novas fronteiras e projetam possíveis consequências futuras ainda imprecisas. Este seria o problema a enfrentar: diante da lacuna normativa, com base em que instrumentos o sistema do Direito Ambiental brasileiro poderia apresentar respostas aos riscos nanotecnológicos?

As nanotecnologias serão, portanto, a tecnologia objeto de abordagem deste artigo, e para melhor compreensão, faz-se necessário explicar seu conceito. As nanotecnologias podem ser compreendidas pela acepção da 
palavra, o prefixo nano vem do grego nânos, que significa anão, muito pequeno (MARANHÃO, 2008). Assim, a "área do conhecimento que estuda os princípios fundamentais de moléculas e estruturas, nas quais pelo menos uma das dimensões está compreendida entre cerca de 1 e 100 nanômetros são as nanotecnologias. O nanômetro, representado pela abreviação $\mathrm{nm}$ é a bilionésima parte do metro, ou seja: $10^{-9}$ do metro. Também pode ser explicado dividindo o número 1/1.000.000.000, ou, $0,000000001 \mathrm{~m}$, ou que o nanômetro é nove ordens de grandeza menor que o metro. Logo, as nanotecnologias são a aplicação destas nanoestruturas em dispositivos nanoescalares utilizáveis (ALVES, 2004). As nanotecnologias têm inúmeras aplicações práticas, as quais já estão sendo comercializadas, sendo mensurado hoje um número de 8.794 produtos no mundo que contém nanotecnologia (NPD, 2019).

As perspectivas futuras ainda estão em pesquisa, mas já corroboram o fascínio por essa tecnologia revolucionária que está e será aplicada na agricultura, setor automotivo, construção, cosméticos, eletrônicos, meio ambiente, alimentação, medicina, entre tantos outros setores. Mas, ao mesmo tempo, as nanotecnologias representam sérios riscos; no meio ambiente os efeitos relacionados às nanopartículas podem surgir em função de sua maior permeabilidade, capacidade de dispersão, persistência, absorção e potencial para serem transformadas ou interagir com outros contaminantes que podem ter efeitos sobre os ecossistemas aquáticos e terrestres quando liberados no meio ambiente. Portanto, em uma escala nano, as características físico-químicas tendem a sofrer modificações que podem gerar inclusive efeitos tóxicos. Neste ponto, surge a questão dos efeitos indesejados, muitos dos quais ainda são completamente desconhecidos. Logo, paira uma considerável incerteza científica quanto aos riscos de danos ambientais decorrentes das nanotecnologias, especialmente referentes às nanopartículas.

Eventos diferentes devem ser esperados, novos efeitos e novas possibilidades são os seus resultados. Por conta disso, um elemento desenvolvido com um objetivo positivo poderá trazer consequências ambientalmente negativas se disposto em um ambiente não premeditado no momento de sua criação, como apontam indícios provenientes de estudos toxicológicos. Na hipótese do problema, compreende-se que, para dar conta também dessa realidade, além de todas as outras situações tuteladas pelo Direito Ambiental, são necessários novos instrumentos capazes de adequar-se rapidamente a esse novo contexto de riscos e 
incertezas, no qual é preciso considerar também a prudência quanto a restrições ou impedimentos capazes de representar obstáculos à ciência e ao desenvolvimento, sem desconsiderar a responsabilidade e os riscos futuros.

Partindo da constatação de que se vive um contexto complexo em que as nanotecnologias apresentam-se como solução para muitas demandas da sociedade, faz-se necessário estabelecer novas possibilidades pelo sistema do Direito, sobretudo no âmbito ambiental, para superar essas dificuldades de tutela que se aplicam somente às estruturas tradicionais do Direito.

\section{O DIREITO AMBIENTAL E SUAS ESTRUTURAS TRADICIONAIS DE TUTELA}

O Direito e suas estruturas tradicionais têm diante de si um contexto complexo e dinâmico que exige constantes aportes inovadores, inclusive porque o ambiente tecnológico tem a mesma característica de evolução rápida. Tem-se uma clara interligação entre os riscos de novas tecnologias, os direitos em sentido amplo e as dificuldades de ser encaminhar soluções adequadas. O Direito Ambiental e sua especificidade tem papel relevante, pois sua origem está intimamente relacionada aos Direitos Humanos. Assim, em escala internacional, o Direito Ambiental evoluiu para o acaloramento das discussões internacionais com o objetivo de proteger e melhorar o produto gerado pela interação humana e o meio ambiente, pois este já sofreu os impactos diante dos perigos de degradação ambiental trazidos pela Revolução Industrial (NAZO; MUKAI, 2002). Inúmeras mudanças ocorreram, necessidades foram atendidas e criadas e o consumo passou a ser mais um elemento de complexidade social.

Nesta conjunção, a era em que a humanidade se situa é aquela identificada como sendo a do Antropoceno, ou seja, a era do Homem, em que a sociedade e seu entorno são pensados a partir da centralidade do homem, assim tudo que é pensado e realizado é por si e para si. O humano age como "observador e manipulador em um grande laboratório, com dois elementos para experiências mutacionais e tecnológicas: o Planeta e as pessoas" (PELLIN; ENGELMANN, 2018, p. 132).

Esse contexto levou a consequências, tanto que na Europa desde o início dos anos 70 , os países industrializados começavam a reconhecer que tinham problemas causados pela poluição. Os graves acidentes ecológicos, com sérios impactos ambientais, econômicos e humanos, 
demonstraram a importância do tema meio ambiente. Tais circunstâncias obrigaram os Estados a tomar medidas para controlar os danos ambientais, surgindo a consciência de que quando "os problemas ambientais assumem proporções graves, a intervenção do Estado a posteriori, reparando o dano, compensando as vítimas, ou responsabilizando os poluidores pelos atos de poluição cometidos, não é o meio mais adequado e eficiente de lidar com esses problemas" (ARAGÃO, 2011, p. 36). A autora ressalta o aspecto inclusive econômico das discussões internacionais sobre a proteção ambiental:

[...] a disparidade entre os elevados custos de produção das empresas, situadas nos países com políticas ambientais rigorosas baseadas no princípio do poluidor-pagador, e os custos de produção, mais baixos, das empresas suas concorrentes, radicadas em países que não desenvolveram qualquer política de proteção do ambiente (ou então que a desenvolvem baseando-se no princípio oposto do financiamento público das medidas e proteção do ambiente), gera desigualdades, na competitividade das empresas, que provêm simplesmente da falta de equivalência entre as condições de mercado em que se inserem (ARAGÃO, 2011, p. 37).

Os sistemas de desenvolvimento estavam somente alicerçados em uma visão clássica de desenvolvimento e crescimento econômico, fundado em um industrialismo cuja regra é o acúmulo de capital e a produção de riqueza, sendo ignorada a preservação dos recursos naturais, uma vez que são limitados e finitos. Leite, por sua vez, concorda em dizer que a problemática ambiental questiona os processos econômicos e tecnológicos que estão sujeitos à lógica de mercado, resultando em degradação do ambiente e prejudicando a qualidade de vida (LEITE; AYALA, 2011, p. 26-27).

Esse contexto justificou, nos anos 1970 e 1980, a adoção de medidas de proteção do meio ambiente por meio de instrumentos internacionais. Assim, a Declaração de Estocolmo, aprovada na Conferência da Organização das Nações Unidas (ONU) sobre o Meio Ambiente Humano (1972) e a publicação, na mesma época, do relatório Clube de Roma sobre os limites do crescimento. Esses documentos serviram de modelo ético para a comunidade internacional, abrindo o caminho para que as constituições nacionais positivassem o meio ambiente ecologicamente equilibrado como um direito humano fundamental (KRELL, 2013).

O Brasil participou desses movimentos de direito internacional, sendo que em 1981, inspirado na Convenção de Estocolmo 1972, foi promulgada a Lei da Política Nacional do Meio Ambiente (PNMA) (BRASIL, 1981). 
Antes da PNMA, em 1973, foi criada a Secretaria Especial do Meio Ambiente (SEMA), orientada para a conservação do meio ambiente e o uso racional dos recursos naturais (BRASIL, 1973). A SEMA foi extinta pela Lei n. 7.735/1989 que criou o Instituto Brasileiro do Meio Ambiente e dos Recursos Naturais Renováveis (IBAMA) (BRASIL, 1989).

A PNMA objetiva preservar, melhorar e recuperar a qualidade do meio ambiente para fins de desenvolvimento social e econômico, bem como proteger a dignidade humana. Nos incisos do art. $2^{\circ}$ a PNMA elenca os princípios que deverão ser seguidos para concretizar os objetivos previstos em seu caput. Os incisos I, IV e VI têm especial relação com os riscos apresentados pelas nanotecnologias, dadas as potencialidades de danos, que podem vir a infringir esses princípios de proteção do meio ambiente (BRASIL, 1981).

No mesmo sentido, o art. $4^{\circ}$ da PNMA prevê a compatibilização do desenvolvimento econômico com a preservação ambiental, uma realidade pertinente às discussões sobre o desenvolvimento das nanotecnologias, em que o incentivo econômico é presente, porém há uma inconsciente falta de preocupação com os riscos ambientais dos novos produtos com nanotecnologias, pois os mesmos já estão sendo comercializados, quando ainda não são totalmente conhecidos seus possíveis resultados negativos (BRASIL, 1981).

Mesmo com toda a sua amplitude, a PNMA não era suficiente para impor a proteção necessária ao meio ambiente, e assim, a riqueza de "terra e arvoredos", que surpreendeu e encantou Pero Vaz de Caminha em 1500 teve sua proteção fortemente reconhecida e hierarquizada somente na Constituição Federal de 1988 (BENJAMIN, 2011, p. 77). Essa disposição constitucional foi um salto de "Estado tradicional de Direito para um Estado atento às necessidades de preservar o meio ambiente para as gerações futuras, como direito e dever de todos" (LEITE; AYALA, 2011, p. 34).

Antunes ressalta que a Constituição trouxe importantes inovações à questão ambiental, tendo em vista que nas Constituições anteriores a menção aos recursos ambientais não era feita de maneira sistemática, sem que se pudesse afirmar a existência de um sistema constitucional de proteção ambiental. Isso decorreu da ausência de preocupação com a conservação dos recursos naturais ou com seu uso racional, não sendo o meio ambiente, à época, detentor de um conceito jurídico merecedor de uma tutela autônoma (ANTUNES, 2016).

Entre os artigos da Constituição Federal de 1988, o art. 225 refere-se 
especialmente às questões ambientais, determinando que "todos têm direito ao meio ambiente ecologicamente equilibrado, bem de uso comum do povo e essencial à sadia qualidade de vida, impondo-se ao Poder Público e à coletividade o dever de defendê-lo e preservá-lo para as presentes e futuras gerações" (BRASIL, 1988). Por isso, o caráter jurídico do meio ambiente ecologicamente equilibrado é de um bem de uso comum do povo. Consequentemente, "a realização individual deste direito fundamental está intrinsecamente ligada à sua realização social” (DERANI, 2008, p. 245). É, portanto, um dos direitos humanos fundamentais (ANTUNES, 2016).

Relevante lembrar que a preocupação dos movimentos internacionais objetivava o controle da poluição e a subjetivação do direito do meio ambiente como um direito fundamental humano. Assim, as normas disciplinadoras dos problemas ambientais de primeira geração estão na dimensão antropocêntrica, posicionando a dignidade da pessoa humana no centro da moralidade ambiental (LEITE; AYALA, 2011). Essa busca pela dignidade alicerçou os referidos movimentos em busca de melhores condições de vida, diante da poluição, falta de saneamento básico, entre outras condições essenciais (ANTUNES, 2016).

A própria constitucionalização do ambiente emerge em fórmula estritamente antropocêntrica, espécie de componente mais amplo da vida e dignidade humana, com a titularidade conferida, inclusive, às gerações futuras. Benjamin refere que componentes biocêntricos já são borrifados no texto constitucional da segunda geração ou na leitura que deles se faça. Especialmente quando a vinculação normativa não é exclusivamente voltada a interesses de cunho estritamente utilitarista, mas sim protecionista. Também cita que "o legislador constitucional não hesitou em nela reconhecer valor intrínseco, estatuindo deveres a serem cobrados dos sujeitos-humanos em favor dos elementos bióticos e abióticos que compõe as bases da vida". Mas, o autor ressalta que de uma forma ou de outra, "o paradigma do homem como prius é irreversivelmente trincado" (BENJAMIN, 2011, p. 130-131).

$\mathrm{Na}$ perspectiva de Antunes, o centro de gravitação do Direito Ambiental é o ser humano. Assim, apesar da tentativa de ruptura com o antropocentrismo, quando o Direito Ambiental visa proteger a vida animal e vegetal, não se altera o centro de gravitação do ser humano para novos sujeitos de direito (animais e vegetais). O Direito positivado é uma construção humana para servir aos propósitos humanos, então, mesmo que o Direito esteja evoluindo em respeito às demais formas de vida, esta não é 
suficiente para deslocar o eixo ao redor do qual circunda a ordem jurídica - o ser humano (ANTUNES, 2016).

Leite, com uma posição intermediária, observa que os problemas ambientais de primeira geração não são estanques. Embora constituam pressupostos para as normas de controle antropicamente centradas (primeira geração), não estão restritos a um determinado período. Os problemas ambientais ou a interpretação desses problemas, sejam eles de primeira ou de segunda geração, não se excluem, mas coexistem atualmente, exigindo um sistema jurídico com mecanismos de compatibilização (LEITE; AYALA, 2011). Nestes termos, Ayala se refere aos riscos apontados pela segunda geração, que exigem uma maior preocupação em legislar pela proteção atual, mas também prevendo o futuro desejado:

\footnotetext{
Os riscos de segunda geração requerem respostas no plano de proteção reforçada para as presentes e para as futuras gerações, mas também a projetos existenciais diferenciados, integrados em uma nova cultura constitucional que ganha importância nesse cenário, moralmente aberta e plural, capaz de integrar comunidades morais diferenciadas e de atender a demandas por proteção até então desconhecidas ou de tímida consideração, ao menos pela comunidade jurídica nacional. (AYALA, 2013, p. 244).
}

Na Constituição Federal de 1988, além das previsões de proteção do art. 225, prevê-se uma harmonia entre os diferentes dispositivos que visam a proteção do meio ambiente, bem como sistematiza a proteção entre os demais entes federados (União, Estados, Municípios e Distrito Federal), nos artigos 23 e seguintes (BRASIL, 1988). Diante da competência comum prevista no mencionado artigo, a Lei Complementar n. 140/2011 fixou a cooperação entre a União, os Estados, o Distrito Federal e os Municípios nas ações administrativas decorrentes do exercício da competência comum relativas à proteção das paisagens naturais notáveis, à proteção do meio ambiente, ao combate à poluição em qualquer de suas formas e à preservação das florestas, da fauna e da flora (BRASIL, 1981). Com o advento da Constituição Federal de 1988, o art. 225 possibilitou a elaboração de legislações específicas, diante das previsões estabelecidas nos incisos do mencionado artigo (BRASIL, 1988).

Constata-se que sistema do Direito Ambiental brasileiro objetiva evitar a ocorrência dos danos ambientais e recuperar as consequências negativas causadas pelo evento. Desta maneira o "dano ambiental deve ser compreendido como toda lesão intolerável causada por qualquer ação humana (culposa ou não) ao meio ambiente, diretamente, como macrobem 
de interesse da coletividade, em uma concepção totalizante e, indiretamente, a terceiros" (LEITE; AYALA, 2011, p. 104).

O licenciamento ambiental é um importante instrumento de controle ambiental para as atividades que, em razão de suas características e dimensões, são potencialmente capazes de causar degradação ambiental (ANTUNES, 2016). Aos procedimentos de licenciamento ambiental aplicam-se a Lei Complementar n. 140 (BRASIL, 2011), a Resolução do CONAMA n. 237/1997 (BRASIL, 1997) e demais resoluções CONAMA, bem como estaduais e municipais, de acordo com as competências definidas na Constituição Federal de 1988 e Lei Complementar n. 140/2010 (BRASIL, 1988; 2010).

Dada a importância desse instrumento, em descumprimento das condicionantes da licença ambiental (BRASIL, 1997) ou cometimento de condutas ou atividades consideradas lesivas ao meio ambiente, os infratores sendo pessoas físicas ou jurídicas, estão sujeitos às sanções penais e administrativas, e à obrigação de reparar os danos causados na esfera civil, conforme art. 14, $\S 1^{\circ}$, na PNMA (BRASIL, 1981), a qual foi confirmada na constituição do $\S 3^{\circ}$ do art. 225 (BRASIL, 1988). Ou seja, a Constituição Federal de 1988 determina a tríplice responsabilidade em casos de cometimento de infrações ou danos ambientais. Na Lei de Crimes Ambientais as sanções vão de multa até privação de liberdade, passando por restrições de direitos (BRASIL, 1998). As infrações administrativas ambientais, conforme art. $3^{\circ}$ do Decreto Lei n. 6.514/2008, também são punidas com sanções diversas (BRASIL, 2008). Como terceira parte dessa hélice, a responsabilidade civil ambiental aplica-se como instrumento de reparação, sem a necessidade de comprovação de culpa para gerar o dever de indenizar, ou seja, segue a teoria da responsabilidade objetiva (MACHADO, 2014).

Como se constata, apesar de um complexo Sistema de Direito Ambiental, não fazem parte dos fatos jurídicos os riscos ambientais das novas tecnologias, incluindo nestas as nanotecnologias. Tampouco estão as atividades utilizadoras de nanotecnologias exigidas de licenciamento ambiental ou de atender requisitos especiais para o controle dos riscos de danos ambientais. Isso se revela como um importante problema a ser superado para que se tenha mais segurança, previsibilidade e controle sobre a utilização de produtos que contenham essa tecnologia. Oportuno destacar algumas aberturas normativas já em desenvolvimento, porém sem que se tenha ainda, uma normatização específica para as nanotecnologias no que contempla a perspectiva do risco. 
Um primeiro destaque pode ser feito a uma iniciativa lançada em 2013, denominada a Iniciativa Brasileira de Nanotecnologia (IBN) que tem por objetivo "integrar as ações governamentais para promover o aumento da competitividade da indústria brasileira", e é vinculada ao Ministério da Ciência, Tecnologia, Inovação e Comunicações. A iniciativa está vinculada às "atividades de pesquisa e desenvolvimento nos laboratórios do Sistema Nacional de Laboratórios em Nanotecnologias (SisNANO)", com escopo de melhorar as "infraestruturas e a abertura dos laboratórios para usuários dos setores acadêmicos e empresariais, promovendo a interação e transferência de conhecimento entre a academia e as empresas". As estratégias de implementação são: (i) apoio ao SisNANO; (ii) fomento ao sistema de Redes Temáticas de PD\&I; (iii) estímulo a pesquisa aplicada em Nanotecnologia; (iv) proposição, acompanhamento e avaliação de um modelo-piloto de nanossegurança; (v) incentivo a ações de internacionalização dos atores públicos e privados de nanotecnologia; (vi) fomento a modelos e programas que propiciem a interação entre o setor produtivo e ICTs na área de nanotecnologia (BRASIL, 2019).

Além da participação do Brasil na NanoReg, foram emitidas Portarias e Instruções normativas sobre o tema. A Portaria n. 245/2012 institui o SisNANO como um dos elementos do Programa Nacional de Nanotecnologia, no âmbito da Estratégia Nacional de Ciência, Tecnologia e Inovação e associado ao Plano Brasil Maior (BRASIL, 2012a). Instrução Normativa n. 2/2012 que confere o Regulamento Técnico para integração dos Laboratórios Estratégicos e dos Laboratórios Associados ao SisNANO (BRASIL, 2012b). A Portaria n. 03/2015 institui o Comitê de Auxílio Técnico de Nanotecnologia (CAT NANOTECNOLOGIA), com o objetivo de prestar auxílio técnico à equipe da Secretaria de Desenvolvimento Tecnológico e Inovação na elaboração de diagnóstico opinativo sobre o desempenho das atividades técnicas e administrativas e propostas de aperfeiçoamento das Redes SIBRATEC de Centros de Inovação em Nanomateriais e Nanocompósitos e de Nanodispositivos e Nanossensores, e da iniciativa Modernit-SisNANO (BRASIL, 2015). A Portaria n. 2.228/2017 (BRASIL, 2017) prorroga os trabalhos do CAT Nanotecnologia por 24 (vinte e quatro) meses a partir do vencimento da Portaria SETEC n. 3/2015 (BRASIL, 2015).

Ainda merece destaque o Protocolo de Estabelecimento do Centro Brasileiro-Argentino de Nanotecnologia (CBAN), entre os Governos do Brasil e da Republica da Argentina, firmado em 30 de novembro de 2005, 
com a Portaria n. 259/2016, que dispõe sobre a Coordenação Nacional da Seção Brasileira do CBAN (BRASIL, 2016). No mesmo sentido, O Centro Brasil-China de Pesquisa e Inovação em Nanotecnologia foi criado pela Portaria n. 117/2012, e tem como objetivos: (i) coordenar as atividades envolvendo a cooperação entre Brasil e China em áreas de nanotecnologia; (ii) promover o avanço científico e tecnológico da investigação e aplicações de materiais nanoestruturados; consolidar e ampliar a pesquisa em nanotecnologia, expandindo a capacitação científica, visando explorar os benefícios resultantes dos desenvolvimentos associados a istocações tecnológicas; (iii) desenvolver programas de mobilização de empresas instaladas no Brasil para possíveis desenvolvimentos na área de nanomateriais (BRASIL, 2019).

Existem iniciativas legislativas em andamento. Tramitam dois projetos de lei junto a Câmara dos Deputados Federais: um deles é o Projeto de Lei n. 5.133/2013 que objetiva regulamentar a rotulagem de produtos da nanotecnologia e de produtos que fazem uso da nanotecnologia (BRASIL, 2013a). O outro é o Projeto de Lei n. 6.741/2013 que dispõe sobre a Política Nacional de Nanotecnologia, a pesquisa, a produção, o destino de rejeitos e o uso da nanotecnologia no país entre outras providências (BRASIL, 2013b).

Junto a Associação Brasileira de Normas Técnicas (ABNT) existe uma Comissão de Estudo Especial de Nanotecnologia (ABNT/CEE-089) que tem como âmbito de atuação: (i) normalização no campo de nanotecnologias incluindo: entendimento e controle de matérias e processos em escala nanométrica, tipicamente, mas não exclusivamente, abaixo de 100 nanômetros, em uma ou mais dimensões onde o surgimento de fenômenos dependentes do tamanho usualmente propicia novas aplicações; utilização das propriedades de materiais em escala nanométrica que diferem das propriedades dos átomos individuais, moléculas e matéria (bulk matter) para criar melhores materiais, dispositivos e sistemas que explorem essas novas propriedades. (ii) no que concerne à terminologia $\mathrm{e}$ nomenclatura; metrologia e instrumentação, incluindo especificações para materiais de referência; métodos de ensaio; modelagem e simulações; e práticas de saúde, segurança e meio ambiente com embasamento científico (ABNT, 2019).

Como se percebe pela descrição exposta, o sistema do Direito Ambiental brasileiro apresenta lacunas, uma vez que os fatos nanotecnológicos não estão incluídos em nenhuma norma, especialmente no que se refere ao 
controle dos riscos e danos ambientais. Para tanto, esses riscos apresentam-se como um verdadeiro desafio para o Direito, uma vez que a velocidade do desenvolvimento das tecnologias não é acompanhada pelo Direito.

\section{TUTELA DAS NANOTECNOLOGIAS PELO SISTEMA DO DIREITO AMBIENTAL: DIFICULDADES E POSSIBILIDADES}

Em virtude da lacuna legal que o sistema revela, faz-se necessário aprofundar as dificuldades enfrentadas pelo sistema do Direito Ambiental brasileiro para incorporar os riscos nanotecnológicos. Dada a inexistência de norma jurídica específica sobre as nanotecnologias, buscar-se-á, utilizando-se dos princípios do sistema do Direito Ambiental brasileiro, demonstrar um possível caminho de aplicabilidade empírica.

A abordagem de Mota (2008) sobre o tema revela uma importante retrospectiva para a compreensão do cenário atual com relação à responsabilidade civil diante dos riscos tecnológicos. O autor explica que, durante o século XIX, a obrigação moral de cada cidadão em relação a si próprio e aos demais tinha mais importância que as obrigações jurídicas. $\mathrm{O}$ cidadão era responsável e prudente com sua liberdade, o que istocava em tomar as providências para proteger a si e a sua família. Assim, as vítimas de infortúnios, eram sempre tidas como as únicas autoras de seu destino, devendo agir com prudência. No século XX, com o sistema de seguridade social, "as obrigações legais tenderam a se tornar mais importantes que as obrigações morais". Novos direitos sociais emergiram o sentimento de que cada cidadão tinha o direito de ser compensado pelos danos resultantes de eventos em sua vida. Essa nova ótica de pensamento resultou em grande medida em um sentimento utópico com relação à capacidade da ciência e da tecnologia de prever e controlar todos os riscos. Isso permitiu a estruturação de sistemas de proteção social, que se baseiam na presunção de que todos os riscos são mensuráveis. "Desse modo, um sentimento de solidariedade social baseado em riscos mensuráveis substituiu o sentimento individual de obrigação moral" (MOTA, 2008, p. 180-211).

Dessa maneira, o sistema se estruturava sob o signo de uma igualdade econômica em que todos têm o direito de ser protegidos de uma generalizada mensuração dos riscos, prevendo a consequente possibilidade de plena reparação dos danos e a irrestrita atribuição de nexo de causalidade. Atualmente, porém, essa estrutura institucional se tornou inadequada diante dos novos riscos das sociedades industriais complexas os quais, 
especialmente os relacionados ao meio ambiente, são impossíveis de serem mensurados pela ciência. "A noção de incerteza substituiu a noção de probabilidade, o que significa uma admissão da incapacidade da sociedade em prever perdas catastróficas irreversíveis" (MOTA, 2008, p. 180-211). Embora a sociedade moderna esteja comprometida com a contínua aquisição de conhecimento, uma situação paradoxal emerge: "novos e maiores conhecimentos revelam amiúde novo e maior desconhecimento" (HOFFMANN-RIEM, 2015, p. 17).

Os riscos associados à tecnologia ou processos permeados por elevados graus de incerteza científica assumem os debates e diálogos nacionais e internacionais diante de sua capacidade de comprometer a existência de todas as formas de vida (AYALA, 2013). Todavia, há a consciência de que os denominados riscos do desconhecimento ou da incerteza não podem ser evitados. "O benefício esperado ainda não é certo; do mesmo modo, não se sabe se os riscos para o bem comum ou para a realização de interesses individuais serão resolvidos. $\mathrm{O}$ direito tem que levar em consideração tal incerteza" (HOFFMANN-RIEM; 2015, p. 27).

A gestão dos riscos ecológicos começa por ser um problema científico e técnico, iniciado com a identificação da situação e desenvolvido por meio da criação de estratégias ou alternativas de ação disponíveis "quando", "como", e "na medida em que" os efeitos dos riscos presumido se verifiquem. Por isso, é preciso incorporar a incerteza no Direito, istocando sua reinterpretação e busca de formas mais flexíveis de manifestar, desde logo, os princípios gerais e o uso de cláusulas gerais (GARCIA, 2015).

Percebe-se que a ciência jurídica reluta em explorar o papel do Direito na prevenção, controle e acompanhamento das inovações, contentando-se em indicar as condições que fazem uma decisão judicial ser legítima; no entanto, isto diante das nanotecnologias não é suficiente (HOFFMANN-RIEM, 2015). Logo, essa compreensão do Direito diante das incertezas dos riscos tecnológicos, especialmente os nanotecnológicos, exige uma consideração reforçada sobre a nova configuração dos problemas ambientais (AYALA, 2013). Assim, se por um lado o Direito tende a ser conservador, de outro lado esse conservadorismo é desafiado pela velocidade acelerada da difusão do conhecimento, promovido pelas tecnologias (SILVA, 2017).

Uma questão merece uma consideração reforçada: a compreensão que se deve ter sobre a nova configuração dos problemas ambientais (AYALA, 2013). Nesse sentido, o termo disrupção, mencionado por Clayton Christensen, professor da Universidade de Harvard, significa o 
rompimento ou a superação de algo preexistente, dando origem a uma nova solução mais eficiente e de fácil acesso, seja do ponto de vista econômico, seja do ponto de vista operacional (SILVA, 2017). Com uma visão crítica, Garcia $(2015$, p. 66; 419) expõe a posição do Direito diante dos desafios tecnológicos:

A aliança entre a ecologia enquanto ciência, no estágio de evolução em que se encontra e a realidade da ação comunitária, particularmente técnico-industrial, deu origem a um saber fazer, a um agir direcionado e adequado à preservação da qualidade do patrimônio natural e dos ciclos de vida na Terra. [...] Se o "ser" do Direito, enquanto sistema normativo, está na lei - problema ontológico - e se esta, pela estrutura geral e abstrata, se revela inadequada para responder a situação de ignorância e incerteza científica, então o problema ontológico do Direito renovase pertinentemente. Continuar o discurso técnico-jurídico assente na norma, geral e abstrata, e na sua interpretação e aplicação aos casos concretos, e ensiná-lo acriticamente nas universidades - lembra a história do barco que naufraga enquanto o comandante e a sua equipagem recebem lições de navegação.

Os processos de inovação mostram que as premissas dos instrumentos jurídicos já não são estabelecidas com base no direito tradicional (HOFFMANN-RIEM, 2015). Isso ocorre, em grande medida, porque as normas jurídicas não contêm alternativas de ação. Garcia defende que a gestão dos riscos ecológicos não pode integrar o sistema de normas jurídicas porque a coerência interna do sistema não produz um quadro de previsibilidade de ação ordenada aos seus destinatários, como a gestão do risco ecológico exige. "A norma pode atribuir aos peritos o poder de decisão. Mas não pode assumir o resultado do exercício desse poder no momento em que se exerce e com os conhecimentos nesse momento disponíveis" (GARCIA, 2015, p. 428).

Como exemplo para a compreensão da diferença entre o sistema jurídico e as regras técnicas diante das novas tecnologias, Garcia menciona que uma regra é questionada quando o desenvolvimento científico a superou ou foi evidenciado um contraste entre a experiência derivada de sua aplicação e aquela que é o conhecimento empírico de situações paralelas. Logo, a revisão da regra é consequência do referido questionamento e da prova produzida em razão desse questionamento. Conclui-se assim que as regras técnicas lidam com a incerteza científica como um fenômeno natural, pois essa alteração não envolve ruptura, não convoca um movimento patológico, como acontece nas normas jurídicas (GARCIA, 2015).

Portanto, o sistema do Direito Ambiental brasileiro deve estar alinhado para se adaptar (WEYERMÜLLER, 2014) às necessidades práticas 
impostas pelas nanotecnologias, para almejar as melhores possibilidades hoje disponíveis para o controle dos riscos de graves danos ambientais. Em que medida o Direito poderá abranger esse potencial é algo incerto que sempre estará em discussão acerca dos métodos de interpretação do Direito e na forma correta de aplicação das leis, uma vez que as tecnologias e os conhecimentos sobre estas sempre estão em constate mutação (HOFFMANN-RIEM, 2015).

Em suma, no quadro do sistema jurídico normativo é impossível concluir, pelo significado, a relevância e os efeitos jurídicos das transformações dos conhecimentos e da evolução técnico-científica. Entendido como sistema normativo, o Direito permite à comunidade confiar na previsibilidade, fruto de sua completude, coerência e não contraditoriedade, mas não pode, sem se descaracterizar, incorporar a gestão do risco. Assim, é preciso ter clara a noção de que absorver no sistema jurídico a gestão do risco significa instalar no sistema de Direito não só lacunas de conhecimento como também ambiguidades e incertezas que substituiriam sua completude, coerência e não contraditoriedade. Por isso, a perda de autonomia do Direito e do sentido de ordem de validade seria sua consequência (GARCIA, 2015).

Verifica-se, então, que os fatos nanotecnológicos não estão incorporados em nenhuma norma pertencente ao sistema do Direito Ambiental brasileiro. Portanto, questiona-se quais seriam as respostas do Direito em caso de ocorrência de um dano ambiental com nanotecnologias? Como enfrentar essa incerteza quando a realidade impuser a necessidade de apuração de danos, responsabilidades e reparações?

Esse quadro de incertezas se fundamenta no fato de que ainda são desconhecidos os danos nanotecnológicos em relação aos possíveis impactos no meio ambiente. Além disso, verifica-se que existe uma gama de produtos que já estão no mercado (conforme mencionado na Introdução) e que são compostos com nanotecnologias. Para tanto, a pergunta sem resposta ainda permanece: de que maneira o sistema do Direito Ambiental brasileiro se posicionaria em caso de dano causado pelas nanotecnologias ao meio ambiente?

É notório que o sistema do Direito é quem define "os problemas que o sistema do Direito pode observar e decidir. Os problemas que não são parte do sistema do Direito não são problemas, não existem" (ROCHA, 2017, p. 180). Mas será que os problemas de risco nanotecnológico não são problemas reais e exigem uma resposta do sistema do Direito Ambiental brasileiro? 
Ademais, salienta-se ainda que no caso das nanotecnologias, os riscos apresentados estão intimamente relacionados aos riscos associados a outras substâncias químicas e aos métodos de fabricação. Os riscos são diferentes de acordo com suas especificidades. Por exemplo, a nano-prata tem propriedades diferentes da prata padrão. Assim, uma lei aplicável às nanotecnologias precisa reconhecer que o tamanho pode afetar as propriedades. Logo, mais diagnósticos são necessários sobre como produtos cujos riscos ainda estão sendo investigados são gerenciados (MOSES, 2013).

É possível afirmar que uma lei aplicável às nanotecnologias precisa estar em constante atualização ou adaptação (WEYERMÜLLER, 2014), dadas as descobertas tecnológicas tanto de novos produtos quanto dos riscos maiores ou menores que os anteriormente conhecidos. Moses refere a crítica do descompasso da evolução na relação entre direito e tecnologia, em que "a tecnologia muda como uma lebre e o enquadramento na regulamentação como uma tartaruga". Assim, um regulamento que visa as nanotecnologias, quase que inevitavelmente se tornará obsoleto (MOSES, 2013).

A inovação tecnológica torna os processos de produção mais complexos e acelera o ritmo das modificações desses (FRYDMAN, 2016). Essas modificações pertencem às racionalidades de cada subsistema social e estão a eles vinculadas, quanto mais impreciso for o sistema, mais forte será a normatividade que decorre da análise da relação do sistema com a dada realidade empírica. Essa normatividade é ainda mais pronunciada em sistemas associados com as leis da natureza. Fenômenos como gravidade, termodinâmica, fotossíntese, entre outros, criam sistemas de conhecimento sobre como a natureza opera em várias áreas. Tais normas são invisíveis e desconhecidas antes de serem articuladas pela ciência (HYDÉN, 2015).

No estágio inicial, no entanto, pouco se sabe sobre a nova tecnologia, os riscos inerentes e os danos que pode causar. Assim, surge o paradoxo da incerteza, pois mesmo diante da falta de conhecimento acerca dos riscos de cada produto com nanotecnologia, não poderia o Estado assumir a totalidade da responsabilidade por sua segurança. Por esse motivo, os atores privados - produtores, distribuidores e usuários industriais - estão sendo cumulados de responsabilidades. Esses atores, ao longo da cadeia de valor, devem estar vinculados por meio de comunicação comum, bem como deve haver a cooperação, com a troca de informações para poderem assumir maior responsabilidade sobre o controle dos riscos. Nesse cenário, são os 
atores privados que devem ajudar a identificar os riscos potenciais com antecedência, mediante soluções inovadoras. Isso conduz a um processo de geração de conhecimento entre as partes interessadas, sob a estimulante ameaça de que a proibição de uso de produtos químicos é possível se o controle de riscos não é alcançado (HOFFMANN-RIEM, 2015).

Engelmann sugere que se propugna uma responsabilidade civil ancorada no "Direito de Danos, que se projeta para o futuro e as incertezas de danos sobre os reais efeitos que a nanotecnologia efetivamente poderá gerar" (ENGELMANN, 2018, p. 399-344). A formulação Direito de Danos é oportuna em razão do pronunciamento da precaução como ponte-conexão em uma provável tentativa de estabilização das expectativas cognitivas por meio do sistema do Direito (ENGELMANN, 2018). O Direito de Danos alteraria assim, a perspectiva do intérprete, ao deslocar o âmbito de investigação da conduta do lesador para o dano (in dúbio pró-vítima) (FROTA, 2008).

É preciso admitir que onde há tecnologia há risco. Para tanto, na perspectiva da responsabilidade civil, cabe uma nova óptica da responsabilização diante do Direito de Danos com a flexibilização do nexo causal, especialmente em razão do caráter grave e irreversível dos danos potenciais que as nanotecnologias poderão produzir (ENGELMANN; PORTO BORJES; GOMES, 2014).

Frydman concorda com o fato de que o meio privado precisa cuidar de como seus produtos e serviços estão sendo fabricados e entregues. Seguindo as condições ambientais e de trabalho aceitáveis, sem violar nem se tornar cúmplice de violações dos direitos fundamentais das pessoas e no que diz respeito a suas atividades (FRYDMAN, 2016). Essa responsabilidade está relacionada com o surgimento de governança por meio da avaliação: avaliações tecnológicas para prever a evolução social e impactos negativos das novas tecnologias. Essas avaliações devem ser realizadas ex ante, antes da decisão de adotar a nova tecnologia, e esse é um passo importante. Todavia, percebe-se que houve pouca investigação empírica dos impactos reais das novas tecnologias, uma vez que diversos produtos sobre os quais pouco se sabe já estão sendo comercializados (WIENER, 2004). Hohendorff et al. (2018, p. 181) adicionam, ainda, que "há que se pensar em uma ética da responsabilidade para o futuro que pretende uma 'nova' responsabilidade, não só direcionada aos fatos pretéritos, mas, principalmente, aos futuros danos, em uma exigência de prevenção e de precaução". 
No que pertine ao contexto de regulação, importante é considerar o impacto da regulamentação na inovação tecnológica, portanto, é preciso olhar além da regulação da tecnologia. Problemas são encontrados em todos os aspectos históricos, doutrinários e tecnológicos, na medida em que a tecnologia muda, o que coloca em questão a eficácia da prevenção. Ainda, pode-se considerar como os reguladores devem abordar uma nova tecnologia que muda rapidamente diante da incerteza sobre o risco, tanto em relação aos riscos conhecidos como aos desconhecidos. Considerar questões de desenho institucional, em particular com as instituições existentes, tais como agências de instituições especializadas, pode ajudar legisladores e reguladores a gerenciar as mudanças tecnológicas em geral ou em contextos específicos. Todas essas questões estão amarradas à ideia de mudanças tecnológicas. O estudo do impacto de uma mudança no desenho legal e regulatório apresenta, portanto, problemas relevantes (MOSES, 2013).

No âmbito das nanotecnologias, não é surpreendente encontrar leis específicas de tecnologia sendo propostas e promulgadas. Várias cidades e estados nos Estados Unidos estão adotando a nanotecnologia como uma categoria reguladora. Na Europa, cosméticos que contêm nanomateriais já estão sujeitos a disposições específicas (EUR-LEX.EUROPA. REGULATION (EC) n. 1223/2009 OF THE EUROPEAN PARLIAMENT AND OF THE COUNCIL of 30 November 2009 on cosmetic products), que incluem na segurança os requisitos de rotulagem (MOSES, 2013). Diloreto, fundador da Nanoreg, menciona que "as rodas lentas do governo federal evoluíram para serem mais reativas do que pró-ativas [sic] e é por isso que questões importantes muitas vezes precisam atingir um estágio crítico antes que qualquer ação seja tomada" (DILORETO, 2010).

No mesmo percurso, Brownsword e Yeung (2008) compreendem que o desafio da conexão regulatória é um dilema da novidade. Eles descrevem o descompasso entre as leis atuais e as abordagens regulatórias que estão projetadas para o panorama tecnológico do passado, exigindo uma constante reconexão. Isso pode ser visto quando novas tecnologias (como a nanotecnologia) entram em um vazio regulatório e quando tecnologias mais antigas, como a fertilização in vitro, se transformam em regimes regulatórios anteriores. $\mathrm{O}$ conceito dos autores de desconexão regulatória é útil na medida em que permite observar a desconexão mesmo quando não há desconexão legal.

Embora seja um dever tentar desenvolver ações testadas e confiáveis, respostas aos desafios, o "simples transplante de uma resposta regulatória 
particular de uma tecnologia para outra nem sempre é apropriado" (BROWNSWORD; YEUNG, 2008). Os espaços são dinâmicos - mesmo que haja uma preocupação pública sobre uma nova tecnologia, com uma crescente aceitação, a contestação pode mudar de questões de segurança, precaução e legitimidade para questões de conformidade e eficácia (MOSES, 2013). Portanto, uma nova tecnologia levanta a questão: será que é preciso desenvolver uma regulação específica para as nanotecnologias? Será que essa regulamentação ou essa necessidade se encaixa em um cenário legal e regulatório preexistente?

Isso é explicado no sentido de que o desafio entre conexão e evolução regulatória é contínuo. Bons mecanismos de adaptação contínua e dinâmica são essenciais. "A tecnologia não irá sempre ser nova, mas estará sempre mudando, apresentando novos problemas legais e regulatórios" (MOSES, 2013). Ora, percebe-se que as evoluções jurídicas passaram por estágios do direito formal e autônomo para o direito substantivo e material, e então passaram para algo que Nonet e Selznick chamaram de direito responsivo e Teubner de direito reflexivo, ou seja, com maior flexibilidade e abertura para o enfrentamento dos desafios da sociedade contemporânea (HYDÉN, 2015). A ecologia ocupa um lugar de destaque, amplia-se a noção de sistema jurídico. Além das normas, ele é também constituído por regras e princípios. O Direito, então, não pode mais fugir a um contato, que sempre existiu dentro da complexidade, com outros sistemas, notadamente, o sistema político e o sistema econômico, que manifestam também outros tipos de problemas, sobretudo em virtude de suas racionalidades próprias e distintas do meio (ROCHA, 2017).

Por isso, nesse cenário, o caos e a crise enfrentados pelo ser humano e a técnica instrumental aliada ao capital têm sido o casamento perfeito. O Direito não tem dado conta de atender a isso, ficando preso em um impasse institucional em virtude do contraste entre a alta globalização de subsistemas sociais e a insuficiência da globalização na política. Para gerenciar esse avanço desequilibrado, o princípio da precaução apresenta-se como uma possibilidade de delimitação dos espaços de atuação, mas precisa sofrer as irritações para se transformar em um princípio atuante (PELLIN; ENGELMANN, 2018).

ENGELMANN (2012, p. 319-344) em releitura a Pontes de Miranda, menciona que o autor contribui, ao descrever o mundo jurídico sob três planos: existência, validade e eficácia. $\mathrm{O}$ ingresso de um fato social no mundo jurídico ocorre pela entrada no plano da existência, subdividido 
em: (i) momento abstrato, que se dá pela descrição da hipótese fática pela norma jurídica; (ii) momento de concreção, incidência da hipótese normativa sobre o fato ou complexo de fatos da vida; (iii) momento de nascimento do fato jurídico, que é a subordinação do fato ou conjunto de fatos aos delineamentos preliminarmente inseridos de modo abstrato no bojo da norma jurídica.

Com essa interpretação, Engelmann propõe uma revisão da teoria do fato jurídico de Pontes de Miranda para responder às questões das nanotecnologias. Esclarece que não se propõe substituição da teoria, mas um realinhamento criativo para conferir à teoria pontesiana mais flexibilidade e abertura, potencializando a produção dos efeitos jurídicos a partir dos desafios nanotecnológicos. Nesse sentido, o autor argumenta que, na época do surgimento da Teoria de Pontes e Kelsen, o referencial era a aplicação das ciências da natureza, as quais não respeitavam as especificidades do Direito e das ciências humanas. Atualmente, o cenário também é desafiador, pois as ciências duras exercem protagonismo na formulação dos pressupostos científicos (ENGELMANN, 2011).

Logo, uma revisão da teoria do fato jurídico não quer dizer que estes estejam necessariamente previstos em lei. Mas podem estar em outras fontes do Direito: na doutrina, costumes, negociações (mediação e arbitragem), Tratados internacionais, princípios gerais de Direito Internacional, entre outros. Logo, faz-se necessária uma "superação do paradigma positivista - notadamente aquele de raiz legalista - que ainda impera no Direito e que sustenta a Teoria do Fato Jurídico pontesiano" (ENGELMANN, 2011, p. 289-308).

Portanto, uma abordagem do sistema do Direito Ambiental brasileiro fundamenta-se nos princípios e parece ser adequada aos desafios impostos pelos riscos nanotecnológicos. Inclusive, a realização do Direito Ambiental por meio de princípios jurídicos tem dois efeitos: encurtar a distância entre o direito e a realidade, e produzir alterações na compreensão da ação dos juristas e técnicos do direito. O novo paradigma do Direito, cuja questão enquanto questão jurídica - convoca, consiste em delimitar a competência do jurista não tanto em eliminar a distância entre a norma e os fatos, mas sobretudo em conduzir o processo racional criativo de descoberta da solução justa, inscrita no ou nos princípios que os fatos apelam, em que tudo é compreendido no complexo quadro de interesses conflitantes nos quais os direitos e deveres se inscrevem (GARCIA, 2015).

Apesar de o Sistema do Direito Ambiental não contar com códigos 
internos capazes de identificar e racionalizar os riscos nanotecnológicos, dentro do sistema existem comandos de princípios que podem servir de instrumentos para a gestão dos riscos nanotecnológicos. Para tanto, chamam-se à aplicação os princípios da prevenção e da precaução, do poluidor-pagador e da adaptação ambiental, cuja finalidade é fornecer respostas ao controle pelo sistema do Direito dos riscos nanotecnológicos. Ademais, o suporte nas demais fontes do Direito, como: na doutrina, costumes, negociações (mediação e arbitragem), Tratados internacionais, princípios gerais de Direito Internacional, entre outros, deve servir conferir maior flexibilidade ao Sistema Jurídico oportunizando um acompanhamento dinâmico da evolução e transformações tecnológicas. Portanto, propõe-se não se afastar por completo do positivismo jurídico, mas realizar um realinhamento criativo do Sistema Jurídico para conferir a este mais flexibilidade e abertura às novidades tecnológicas e, assim, potencializar a produção dos efeitos jurídicos aos desafios dos riscos nanotecnológicos.

\section{CONCLUSÃO}

As possibilidades que as nanotecnologias representam não podem ser ignoradas, pois indicam um novo paradigma tecnológico para o futuro. Várias foram as revoluções tecnológicas já vivenciadas pela humanidade, porém as nanotecnologias significam uma nova fronteira ultrapassada sem possibilidade de retorno.

Não apenas as nanotecnologias representam ao mesmo tempo uma nova etapa da evolução humana como uma clara novidade de riscos futuros. Muitas outras inovações não podem ainda ser consideradas seguras, como é o caso dos transgênicos. Porém, a amplitude das aplicações das nanotecnologias supera qualquer outra em termos de números e multiplicidade de aplicações. Justamente por isso o tema se torna premente e de grande importância para o sistema do Direito Ambiental.

A ausência de norma jurídica, mais precisamente de regra, indica que sequer dentro da perspectiva aqui designada como tradicional do Direto, se tem resposta adequada para as possibilidades futuras de danos que podem advir da utilização em larga escala dessa tecnologia. Instrumentos de tutela tradicionais também encontram dificuldades para promover adequadamente a conciliação entre as necessidades da sociedade e a carga ambiental que elas representam. Assim, mesmo que já houvesse uma resposta objetiva do Direito Ambiental por meio de uma Lei, por exemplo, possivelmente também não se teria segurança. 
Nessa perspectiva, se impõe uma necessária adaptação de instrumentos jurídicos que possam dar conta de tal complexidade, ao menos reduzindo bastante as possibilidades de danos no futuro. Dentro do conjunto de elementos que o Direito tem à disposição, verifica-se que os princípios são possivelmente a resposta mais adequada e já estruturada que pode ser utilizada na tutela das nanotecnologias. Danos que podem advir de possíveis efeitos ainda não conhecidos dos produtos em escala nanométrica, não podem ser controlados apenas pela noção tradicional e positivista do Direito Civil, por exemplo. Assim, visualizar o contexto amplo dos riscos das nanotecnologias é o primeiro ponto a ser considerado. Essa complexidade não pode ser simplesmente combatida por norma restritiva. Um Direito Ambiental adaptado a essas novas demandas precisa considerar de maneira efetiva a aplicação de princípios fundamentadores da ordem jurídica ambiental, com especial destaque para o princípio da precaução. Não apenas uma precaução formal, mas, sobretudo, uma postura realmente antecipadora baseada na premissa da incerteza científica.

Ao final, cumpre relembrar que o problema traçado ao início deste artigo: diante da lacuna normativa, com base em que instrumentos o sistema do Direito Ambiental brasileiro poderia apresentar respostas aos riscos nanotecnológicos?

A hipótese de solução inicialmente traçada partiu da compreensão de que, para dar conta da realidade dos nanotecnológicos, são necessários novos instrumentos criativos capazes de se adequar rapidamente as novidades e ao contexto de riscos e incertezas. Para tais riscos chama-se à aplicação dos princípios da prevenção e da precaução, e do poluidor-pagador, pertencentes a uma lógica de adaptação ambiental, bem como as demais fontes do Direito (doutrina, costumes, Tratados Internacionais, princípios gerais de direito internacional) objetivando respostas aos riscos nanotecnológicos. Tais instrumentos, adaptados a cada realidade de riscos nanotecnológicos, permitem flexibilidade adaptativa ao Sistema Jurídico, permitindo acompanhar a dinamicidade evolutiva das nanotecnologias. Portanto, pode-se concluir que a hipótese de solução inicialmente prevista confirmou-se.

Reformulações do papel do Direito Ambiental são necessárias, assim como uma ampla aplicação de instrumentos flexíveis (princípios, doutrinas, tratados) podem representar um avanço importante para fazer frente ao avanço inexorável das nanotecnologias. Atingir um nível ideal de conciliação entre a defesa do direito a um futuro mais seguro em termos 
ambientais e os benefícios da tecnologia parece ser o grande desafio a ser enfrentado pelo Direito Ambiental na atualidade.

\section{REFERÊNCIAS}

ABNT - ASSOCIAÇÃO BRASILEIRA DE NORMAS TÉCNICAS. Comissão de Estudo Especial de Nanotecnologia (ABNT/CEE-089). Disponível em: http://www.abnt.org.br/cee-89. Acesso em: 21 nov. 2019.

ALVES, O. Nanotecnologia, nanociência e nanomateriais: quando a distância entre presente e futuro não é apenas questão de tempo. Revista Parcerias Estratégicas, Brasília, v. 9, n. 18, 2004. Disponível em: http:// seer.cgee.org.br/index.php/parcerias_estrategicas/article/view/138. Acesso em: 21 nov. 2018.

ANTUNES, P. B. Direito Ambiental. 18. ed. rev. ampl. e atual. São Paulo: Atlas, 2016.

ARAGÃO, A. Direito Constitucional do Ambiente da União Europeia. In: CANOTILHO, J. J. G.; LEITE, J. R. M. Direito Constitucional Ambiental Brasileiro. São Paulo: Saraiva, 2011. p. 32-76.

AYALA, P. A. Direito ambiental da sustentabilidade e os princípios de um direito ambiental de segunda geração na PNMA. In: LOPEZ, T. A.; LEMOS, P. F. I.; RODRIGUES JUNIOR; O. L. (org.). Sociedade de Direito e Direito Privado: desafios normativos, consumeristas e ambientais. São Paulo: Atlas, 2013. p. 243-272.

BENJAMIN, A. H. Direito Constitucional Ambiental Brasileiro. In: CANOTILHO, J. J. G.; LEITE, J. R. M. Direito Constitucional Ambiental Brasileiro. São Paulo: Saraiva, 2011. p. 77-155.

BRASIL. Presidência da República. Decreto n. 73.030, de 30 de outubro de 1973. Cria, no âmbito do Ministério do Interior, a Secretaria Especial do Meio Ambiente - SEMA, e das outras providências. Brasília, DF: Presidência da República, 1973. Disponível em: https://www2.camara.leg. br/legin/fed/decret/1970-1979/decreto-73030-30-outubro-1973-421650publicacaooriginal-1-pe.html. Acesso em: 21 nov. 2019.

BRASIL. Presidência da República. Lei n. 6.938 de 31 de agosto de 1981. Dispõe sobre a Política Nacional do Meio Ambiente, seus fins e mecanismos de formulação e aplicação, e dá outras providências. Brasília, 
DF: Presidência da República, 1981. Disponível em: http://www.planalto. gov.br/ccivil_03/leis/16938.htm. Acesso em: 21 nov. 2019.

BRASIL. Constituição (1988). Constituição da República Federativa do Brasil de 1988. Brasília, DF: Presidência da República, 1988. Disponível em: http://www.planalto.gov.br/ccivil_03/constituicao/constituicaocompilado. htm. Acesso em: 21 nov. 2019.

BRASIL. Presidência da República. Lei n. 73.030, de 22 de fevereiro de 1989. Dispõe sobre a extinção de órgão e de entidade autárquica, cria o Instituto Brasileiro do Meio Ambiente e dos Recursos Naturais Renováveis e dá outras providências. Brasília, DF: Presidência da República, 1989. Disponível em: http://www.planalto.gov.br/ccivil_03/Leis/17735.htm. Acesso em: 21 nov. 2019.

BRASIL. Conselho Nacional Do Meio Ambiente. Resolução n. 237, de 19 de dezembro de 1997. Brasília, DF: Presidência da República, 1997. Disponível em: http://www.mma.gov.br/port/conama/res/res97/res23797. html. Acesso em: 21 nov. 2019.

BRASIL. Presidência da República. Lei no 9.605, de 12 de fevereiro de 1998. Dispõe sobre as sanções penais e administrativas derivadas de condutas e atividades lesivas ao meio ambiente, e dá outras providências. Brasília, DF: Presidência da República, 1998. Disponível em: http://www. planalto.gov.br/ccivil_03/Leis/L9605.htm. Acesso em: 21 nov. 2019.

BRASIL. Presidência da República. Decreto 6.514 de 22 de julho de 2008. Dispõe sobre as infrações e sanções administrativas ao meio ambiente, estabelece o processo administrativo federal para apuração destas infrações, e dá outras providências. Brasília, DF: Presidência da República, 2008. Disponível em: http://www.planalto.gov.br/ccivil_03/_ ato2007-2010/2008/decreto/d6514.htm. Acesso em: 21 nov. 2019.

BRASIL. Presidência da República. Lei Complementar n. 140 de 08 de dezembro de 2011. Fixa normas, nos termos dos incisos III, VI e VII do caput e do parágrafo único do art. 23 da Constituição Federal, para a cooperação entre a União, os Estados, o Distrito Federal e os Municípios nas ações administrativas decorrentes do exercício da competência comum relativas à proteção das paisagens naturais notáveis, à proteção do meio ambiente, ao combate à poluição em qualquer de suas formas e à preservação das florestas, da fauna e da flora; e altera a Lei n. 6.938, 
de 31 de agosto de 1981. Brasília, DF: Presidência da República, 2011. Disponível em: http://www.planalto.gov.br/ccivil_03/Leis/LCP/Lcp140. htm. Acesso em: 21 nov. 2019.

BRASIL. Gabinete do Ministro do Ministério da Ciência, Tecnologia da Inovação. Portaria n. 245, de 5 de abril de 2012 (SisNANO). Brasília, DF: Presidência da República, 2012a. Disponível em: http://www.lex.com. br/legis_23138521_PORTARIA_N_245_DE_5_DE_ABRIL_DE_2012. aspx. Acesso em: 21 nov. 2019.

BRASIL. Gabinete do Ministro do Ministério da Ciência, Tecnologia da Inovação. Instrução Normativa n. 2, de 15 de junho de 2012 (SisNANO). Brasília, DF: Presidência da República, 2012b. Disponível em: http:// www.lex.com.br/legis_23461758_INSTRUCAO_NORMATIVA_N_2_ DE_15_DE_JUNHO_DE_2012.aspx. Acesso em: 21 nov. 2019.

BRASIL. Câmara dos Deputados. Projeto de Lei n. 5.133/2013. Regulamenta a rotulagem de produtos da nanotecnologia e de produtos que fazem uso da nanotecnologia. Brasília, DF: Presidência da República, 2013a. Disponível em: http://www.camara.gov.br/proposicoesWeb/ fichadetramitacao?idProposicao=567257. Acesso em: 21 nov. 2019.

BRASIL. Câmara dos Deputados. Projeto de Lein. 6.741/2013. Dispõe sobre a Política Nacional de Nanotecnologia, a pesquisa, a produção, o destino de rejeitos e o uso da nanotecnologia no país, e dá outras providências. Brasília, DF: Presidência da República, 2013b. Disponível em: http://www. camara.gov.br/proposicoesWeb/fichadetramitacao?idProposicao $=600333$. Acesso em: 21 nov. 2019.

BRASIL. Gabinete do Ministro do Ministério da Ciência, Tecnologia da Inovação. Portaria n. 03, de 6 de maio de 2015 (CAT Nanotecnologia). Brasília, DF: Presidência da República, 2015. Disponível em: http:// www.lex.com.br/legis_26758638_PORTARIA_N_3_DE_6_DE_MAIO_ DE_2015.aspx. Acesso em: 21 nov. 2019.

BRASIL. Gabinete do Ministro do Ministério da Ciência, Tecnologia da Inovação. Portaria n. 259, de 3 de março de 2016. Brasília, DF: Presidência da República, 2016. Disponível em: http://www.lexeditora.com.br/ legis_27110541_PORTARIA_N_259_DE_23_DE_MARCO_DE_2016. aspx. Acesso em: 21 nov. 2019.

BRASIL. Gabinete do Ministro do Ministério da Ciência, Tecnologia 
da Inovação. Portaria n. 2.228, de 6 de abril de 2017 (Prorroga CAT Nanotecnologia). Brasília, DF: Presidência da República, 2017. Disponível em: $\quad$ http://www.mctic.gov.br/mctic/opencms/legislacao/portarias/ migracao/Portaria_SETEC_n_2228_de_26042017.html. Acesso em: 21 nov. 2019.

BRASIL. Ministro do Ministério da Ciência, Tecnologia da Inovação. Centro Brasil-China de Pesquisa e Inovação em Nanotecnologia. Brasília, DF: Presidência da República. Disponível em: http://www.mctic. gov.br/mctic/opencms/tecnologia/tecnologias_convergentes/paginas/ nanotecnologia/NANOTECNOLOGIA.html. Acesso em: 21 nov. 2019.

BROWNSWORD, R.; YEUNG, K. Regulating technologies: legal futures, regulatory frames and technological fixes. Oxford: Hart, 2008.

DERANI, C. Direito ambiental econômico. São Paulo: Saraiva, 2008.

DILORETO, J. We should have seen it coming: states regulating nanotechnology. Nanotechnology Now, 7 set. 2010. Disponível em: http:// www.nanotech-now.com/columns/?article=484. Acesso em: 21 nov. 2019.

ENGELMANN, W. A (re)leitura da teoria do fato jurídico à luz do "diálogo entre as fontes do direito": abrindo espaços no direito privado constitucionalizado para o ingresso de novos direitos provenientes das nanotecnologias. In: STRECK, L. L. MORAIS, J. L. B. (org.). Constituição, sistemas sociais e hermenêutica: anuário do Programa de Pós-Graduação em Direito da Unisinos: mestrado e doutorado. Porto Alegre: Livraria do Advogado, 2011. p. 289-308.

ENGELMANN, W. O diálogo entre as fontes do Direito e a gestão do risco empresarial gerado pelas nanotecnologias: construindo as bases à juridicização do risco. In: STRECK, L. L.; ROCHA, L. S.; ENGELMANN, W. (Org.). Constituição, sistemas sociais e hermenêutica: anuário do Programa de Pós-Graduação em Direito da Unisinos: mestrado e doutorado. Porto Alegre: Livraria do Advogado, 2012. p. 319-344.

ENGELMANN, W. As nanotecnologias e o meio ambiente: entre os riscos e a autorregulação regulada. In: STRECK, L. L.; ROCHA, L. S.; ENGELMANN, W. (Org.). Constituição, sistemas sociais e hermenêutica: anuário do Programa de Pós-Graduação em Direito da Unisinos: mestrado e doutorado. São Leopoldo: Karywa, Unisinos, 2018. p. 245-269. 
ENGELMANN, W.; PORTO BORJES, I. C.; GOMES, T. Responsabilidade civil e nanotecnologias. São Paulo: Atlas, 2014.

EUR-LEX.EUROPA. REGULATION (EC) No 1223/2009 OF THE EUROPEAN PARLIAMENT AND OF THE COUNCIL of 30 November 2009 on cosmetic products. Official Journal of the European Union, 2009. Disponível em: https://eur-lex.europa.eu/legal-content/EN/TXT/ PDF/?uri=CELEX:32009R1223\&rid=1. Acesso em: 2 jun. 2019.

FROTA, P. M. C. Danos morais e a pessoa jurídica. São Paulo: Método, 2008 .

FRYDMAN, B. O fim do Estado de Direito: governar por standards e indicadores. Porto Alegre: Livraria do Advogado, 2016.

GARCIA, M. G. F. P. D. O lugar do Direito na proteção do ambiente. Coimbra: Almedina, 2015.

HOFFMANN-RIEM. W. Direito, tecnologia e inovação. In: MENDES, G. F.; SARLET, I. W.; COELHO, A. Z. P. Direito, inovação e tecnologia. São Paulo: Saraiva, 2015. p. 11-32.

HYDÉN, H. Perspectivas em sociologia do Direito. In: SCHWARTZ, G.; COSTA, R. A. (Org.). Sociology of law on the move. Canoas: UnilaSalle, 2015. p. 67-92.

KRELL, A. J. O meio ambiente nas Constituições estrangeiras e no direito internacional. In: CANOTILHO, J. J. G. et al. (Org.). Comentários à Constituição do Brasil. São Paulo: Saraiva/Almedina, 2013. p. 2079.

LEITE, J. R. M. L.; AYALA; P. A. Dano ambiental: do individual ao coletivo extrapatrimonial. 4. ed. rev. ampl. e atual. São Paulo: Revista dos Tribunais, 2011.

MACHADO, P. A. L. Direito Ambiental Brasileiro. 22. ed. rev. ampl e atual. São Paulo: Malheiros, 2014.

MARANHÃO, R. A. História da nanotecnologia. In: $1^{\circ}$ CONGRESSO DE HISTÓRIA DAS CIÊNCIAS E DAS TÉCNICAS E EPISTEMOLOGIA, 1., 2008, Rio de Janeiro. Anais [...]. Rio de Janeiro: UFRJ/HCTE, 2008. Disponível em: http://www.hcte.ufrj.br/downloads/sh/sh1/Artigos/68.pdf. Acesso em: 21 nov. 2019.

MOSES, L. B. How to think about law, regulation and technology: problems with technology as a regulatory target. Law, Innovation and 
Techonology, 2013. Disponível em: https://papers.ssrn.com/sol3/papers. cfm?abstract_id=2464750. Acesso em: 21 nov. 2019.

MOTA, M. O Princípio da Precaução no Direito Ambiental: uma construção a partir da razoabilidade e da proporcionalidade. Revista de Direito Ambiental, São Paulo, v. 50, p. 180-211, abr./jun., 2008. Disponível em: http://www.revistadostribunais.com.br/maf/app/trail/ document?docguid $=\mathrm{I} 4678 \mathrm{fb} 80 \mathrm{f} 25511 \mathrm{dfab} 6 \mathrm{f} 010000000000$. Acesso em: 2 jun. 2019.

NPD - NANOTECHNOLOGY PRODUCTS DATABASE. Source of information about nanotechnology products. Disponível em: http:// product.statnano.com/. Acesso em: 20 jun. 2019.

NAZO, G. N.; MUKAI, T. O direito ambiental no Brasil: evolução histórica e a relevância do direito internacional do meio ambiente. Revista de Direito Ambiental, São Paulo, v. 28, p. 70-100, out./dez. 2002. Disponível em: http://www.revistadostribunais.com.br/maf/app/resultList/t?\&src=rl\&srgu $\mathrm{id}=\mathrm{i} 0 \mathrm{ad} 82 \mathrm{~d} 9 \mathrm{a} 0000016289 \mathrm{~b} 41 \mathrm{e} 3 \mathrm{ce} 3 \mathrm{~b} 59 \mathrm{a} 0 \mathrm{a} \&$ docguid $=\mathrm{I} 45 \mathrm{c} 3 \mathrm{dc} 50 \mathrm{f} 25511 \mathrm{~d}$ fab6f010000000000\&hitguid $=I 45 \mathrm{c} 3 \mathrm{dc} 50 \mathrm{f} 25511 \mathrm{dfab} 6 \mathrm{f} 010000000000 \& \mathrm{sp}$ os $=1 \&$ epos $=1 \& \mathrm{td}=1 \&$ context $=82 \&$ crumb-action $=$ append $\&$ crumb-label $=$ Documento\&isDocFG=false\&isFromMultiSumm $=\&$ startChunk $=1 \&$ end Chunk=1. Acesso em: 2 jun. 2019.

PELLIN, D.; ENGELMANN, W. A política, a economia e o direito para a efetividade do princípio da precaução: uma visão pluralista. In: RUSCHEINSKY, A.; CALGARO, C.; WEBER, T. (Org.). Ética, direito socioambiental e democracia. Caxias do Sul: Educs, 2018. p. 131-146.

ROCHA, L. S. Observações sobre autopoiese, normativismo e pluralismo jurídico. In: STRECK, L. L. MORAIS, J. L. B. (Org.). Constituição, sistemas sociais e hermenêutica: anuário do Programa de Pós-Graduação em Direito da Unisinos: mestrado e doutorado. Porto Alegre: Livraria do Advogado, 2017. p. 168-181.

SILVA, J. B. L. O efeito disruptivo das inovações tecnológicas frente às ciências jurídicas e sociais. In: FREITAS, R. V.; RIBEIRO; L. C.; FEIGELSON, B. (Org.) Regulação e novas tecnologias. Belo Horizonte: Fórum, 2017. p. 155-164.

WEYERMÜLLER, A. R. Água e adaptação ambiental: o pagamento pelo seu uso como instrumento econômico e jurídico de proteção. Curitiba: Juruá, 2014. 
WIENER, J. B. The regulation of technology, and the technology of regulation. Tecnology in Society, v. 26, p. 483-500, 2004. Disponível em: https://scholarship.law.duke.edu/cgi/viewcontent. cgi?article=1960\&context=faculty_scholarship. Acesso em: 21 nov. 2019. HOHENDORFF, Raquel Von et al. Por que precisamos falar sobre o papel do consumidor final na destinaçãodos produtos nanotecnológicos? Renata Luciane Polsaque Young Blood (Org). Fenômenos sociais e direito. Ponta Grossa: Atena, 2018.

Artigo recebido em: 06/06/2019. Artigo aceito em: 11/07/2019.

\section{Como citar este artigo (ABNT):}

BERWIG, J. A.; ENGELMANN, W.; WEYERMULLER, A. R. Direito ambiental e nanotecnologias: desafios aos novos riscos da inovação. Veredas do Direito, Belo Horizonte, v. 16, n. 36, p. 217-246, set./dez. 2019. Disponível em: http://www.domhelder.edu.br/revista/index.php/veredas/ article/view/1553. Acesso em: dia mês. ano. 